\title{
Inappropriate hospital site selection: A case report
}

\author{
Ahmad Kameli ${ }^{1}$, Majid Dastras² ${ }^{2}$ Mohammad Zarei ${ }^{3, *}$
}

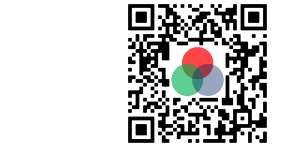

Use your smartphone to scan this QR code and download this article

${ }^{1}$ Nursing Department, Faculty of Nursing, North Khorasan University of Medical Sciences, Bojnurd, Iran

${ }^{2}$ Nursing Department, Faculty of Nursing, Zahedan University of Medical Sciences, Zahedan, Iran

${ }^{3}$ Health in Disaster and Emergencies Department, School of Public Health, Tehran University of Medical Sciences, Tehran, Iran

\section{Correspondence}

Mohammad Zarei, Health in Disaster and Emergencies Department, School of Public Health, Tehran University of Medical Sciences, Tehran, Iran

Email: zareim51@gmail.com

History

- Received: 2020-03-17

- Accepted: 2020-08-19

- Published: 2020-10-31

DOI :10.15419/ajhs.v6i2.469

\section{Check for updates}

Copyright

(C) Biomedpress. This is an openaccess article distributed under the terms of the Creative Commons Attribution 4.0 International license.

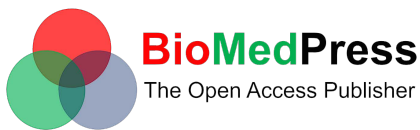

\begin{abstract}
Introduction: Health centers as one of the main urban services, and one of the key factors in assessing the feasibility of sustainable development in cities have a high sensitivity to location and choice of accommodation. Case Report: Shirvan is the largest city after the capital of the province in North Khorasan of Iran. On the southern edge of the city of Shirvan, there is a seasonal river between the city and Ayatollah Hashemi Rafsanjani Hospital. The need to build a solid bridge is essential for safe access to the hospital, which, unfortunately, has not been achieved. The constructed roundabout passes approximately one meter from the river floor. In the spring of 2019, there was heavy rainfall in most parts of the country, and the area was not poor. The rains blocked access to Ayatollah Hashemi Rafsanjani Hospital as water flowed into the seasonal river. Conclusion: A hospital that should help itself to a crisis was itself a cause of the crisis in a short time.
\end{abstract}

Key words: Hospital, Site selection, Crisis, Flood

\section{INTRODUCTION}

Health centers, as one of the main urban services and one of the key factors in measuring the feasibility of sustainable development in cities, are highly sensitive to location and choice of accommodation ${ }^{1}$. Choosing the right and optimal location for deploying medical applications and hospitals is so important that it can be said to deal with human health and life and cannot be neglected because it would cause irreparable health damage ${ }^{2}$.

Hospital Site Selection at the city level and even outside of it is one of the specialties that city planners and managers have paid particular attention to in recent years ${ }^{3}$. In general, hospital location planning should be done separately for each case by urban, environmental, and structural experts, but there are general principles that are common to the whole world and cannot be overstated ${ }^{4}$.

For the construction of a hospital, one of the most important factors in locating it can be said to be the availability of communication and access roads to the hospital $^{5}$. Access to the city's main streets, squares, and intersections are among the most important factors to note ${ }^{6}$. Other infrastructure needed to accommodate the hospital may also include public transportation such as the subway, city buses, and proximity to passenger terminals ${ }^{5}$. Locating in the vicinity of the urban green space and fire stations is also an advantage. Supplying the facilities and equipment needed for the chosen location, such as water, electricity, gas, sewage treatment plant, etc., are important advantages of hospital location ${ }^{5}$. Inhibitors and limits are related to site selection, sex and land restriction, seasonal flooding... 6

\section{CASE REPORT}

Shirvan is the largest city after the capital of the province in North Khorasan of Iran. Shirvan city has two hospitals with a population of about 157,000. Imam Khomeini Hospital, which is the old city hospital, is on the outskirts of one of the city's main streets and is easily accessible to people ${ }^{7}$. Ayatollah Hashemi Rafsanjani's 220 Specialized Hospital Hospital, which was commissioned in May 2016, is about $1 \mathrm{~km}$ from the southern margin of the city ${ }^{8}$. After operating this hospital, most of the general and specialized medical departments were transferred to this hospital. Imam Khomeini Hospital was transformed into a pediatric and gynecological hospital ${ }^{9}$.

On the southern margin of the city, there is a seasonal river between the city and Ayatollah Hashemi Rafsanjani Hospital. The need to build a solid bridge is essential for safe access to the hospital, which, unfortunately, has not been achieved. The constructed roundabout passes approximately one meter from the river floor (Figure 1).

In the spring of 2019, there was heavy rainfall in most parts of Iran, and the area was not poor. The rains blocked access to Ayatollah Hashemi Rafsanjani Hospital as water flowed into the seasonal river. This was at a time when several rivers were flooding in different areas of the city, and all relief organizations and organizations were helping them, and at this time, there 


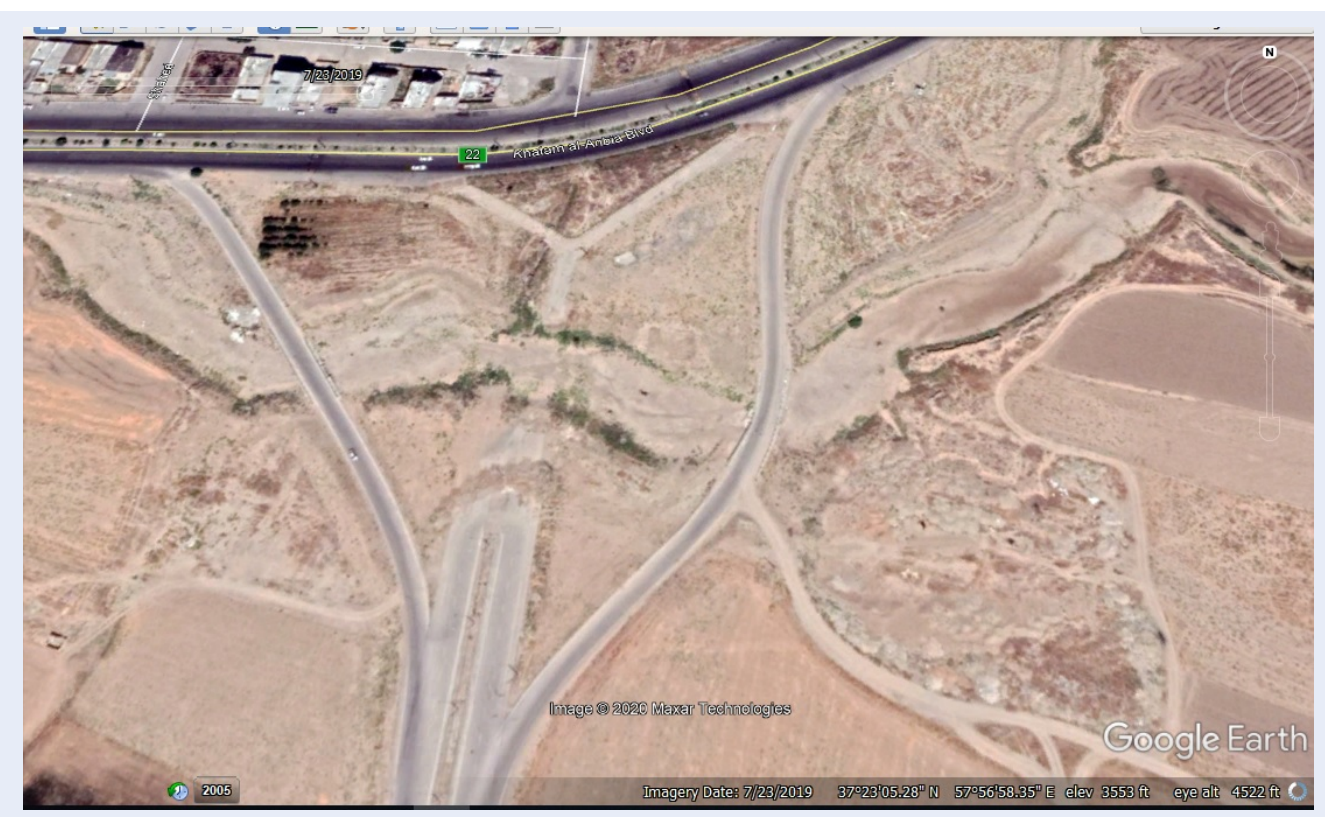

Figure 1: The need to build a solid bridge is essential for safe access to the hospital, which, unfortunately, has not been achieved. The constructed roundabout passes approximately one meter from the river floor

was a greater need to use the hospital's medical facilities for relief. Unfortunately, however, this was not possible due to the lack of safe access to the hospital, and all patients were referred to Imam Khomeini Hospital for Women and Children. The hospital that itself had to help with the crisis was itself a cause of crisis for a short time, and the needs of patients and hospital staff were met and replaced with heavy municipal vehicles.

Field visits show that after a few months, the situation is still the same as before, and no plans have been made to fix the problem and not repeat the problem at the beginning of the year.

\section{DISCUSSION}

It is not mandatory to use all these factors to build a hospital. Depending on the strategy of building hospitals, planners may discuss just some of these. For instance, in 2013, Kim et al. performed hospital placement for the elderly and considered factors that cover the actual health needs of the target group. Therefore, some of the criteria, including environmental issues (air pollution, noise, and sewage), were not considered $^{10}$. In 2011, Soltani et al. used different criteria, likewise urban planning, traffic volume, and travel time, to select a hospital location in Panj Shiraz area. But they didn't include surrounding and land issues in their study ${ }^{11}$. Wu et al. (2007) considered administrative criteria such as regulations, policymakers' attitudes, and even hospital staff demand ${ }^{12}$. They also didn't consider environmental concerns and access to infrastructure, such as major roads. The most important thing that has not been considered in the construction of our study hospital and has caused severe problems is the proper access to the hospital.

Xiao Hua Ho et al. (2014) expanded a model for identifying a suitable location for medical services in a large group of islands in Hainan Province, China. This model was based on minimizing travel distances for customers of these services. In the study, real demand and environmental issues are not considered ${ }^{13}$. The index considered in this study is not considered in the construction of our study hospital.

\section{CONCLUSION}

Despite the crucial role of hospitals in providing medical services in medical emergencies and the impact of hospital position on the quality of these services, few articles have considered the risks as the criteria for selecting a hospital site. Undoubtedly, staying safe and active in emergencies and disasters should be one of the main HSS goals of the Sendai Framework.

\section{ABBREVIATIONS}

None.

\section{ACKNOWLEDGMENTS}

None. 


\section{AUTHOR'S CONTRIBUTIONS}

All authors equally contributed in this study. All authors read and approved the final manuscript.

\section{FUNDING}

None.

\section{AVAILABILITY OF DATA AND MATERIALS}

Not applicable.

\section{ETHICS APPROVAL AND CONSENT TO PARTICIPATE}

Not applicable.

\section{CONSENT FOR PUBLICATION}

Not applicable.

\section{COMPETING INTERESTS}

The authors declare that they have no competing interests.

\section{REFERENCES}

1. Eskandari H. Lessons in passive defense; land use planning from the perspective of passive defense, 1st ed. Tehran: Boustane Hamid publications. 2011;p. 40-76.

2. Parsa MM, Yazdani MH, Pashazadeh M. Optimal Site Selection of Urban Hospitals Using GIS Software in Ardabil City. 2017;16(4):374-388.
3. Moradian MJ, Ardalan A, Nejati A, Boloorani AD, Akbarisari A, Rastegarfar B. Risk Criteria in Hospital Site Selection: A Systematic Review. PLOS Currents Disasters. 2017;Available from: 10.1371/currents.dis.a6f34643f3cd22c168b8c6f2deeae86d.

4. Alavi SA, Ahmadabadi A, Qelichi AM, Pato V, Borhani K. Proper site selection of urban hospital using combined techniques of MCDM and spatial analysis of GIS (Case study: region 7 in Tehran city). 2013;12(2):9-18.

5. Younis MZ, Younies HZ, Okojie F. Hospital financial performance in the United States of America: a follow-up study. La Revue de Santé de la Méditerranée orientale. 2006;12(5):670678.

6. Masser I. Managing our urban future: the role of remote sensing and geographic information systems. Habitat international. 2001;25(4):503-512. Available from: https://doi.org/10. 1016/S0197-3975(01)00021-2.

7. https://www.nkchto.ir/shirvan

8. https://www.irna.ir/news/82527666

9. https://khabarfarsi.com/city

10. Kim Jl, Ruza J, Kam C, Ng S. Evidence-based analyses of hospital site selection for the aging population in Dallas, Texas. In 2nd Annual International Conference Sustainable Design, Engineering and Construction, ICSDEC 2012; 2013. Fort Worth, TX: 2nd Annual International Conference Sustainable Design, Engineering and Construction, ICSDEC . 2012;Available from: https://doi.org/10.1061/9780784412688.034.

11. Soltani A, Marandi EZ. Hospital site selection using two-stage fuzzy multi-criteria decision making process. 2011;5(1):3243. Available from: https://doi.org/10.4090/juee.2011.v5n1. 032043.

12. Wu C, Lin C, Chen H. Optimal selection of location for Taiwanese hospitals to ensure a competitive advantage by using the analytic hierarchy process and sensitivity analysis. 2007;42(3):1431-1444. Available from: https://doi.org/10. 1016/j.buildenv.2005.12.016.

13. $\mathrm{Hu} X \mathrm{XH}$, Lu CZ, Li M, Zhang CH, Zhang H. Mathematical modeling for selecting center locations for medical and health supplies reserve in Hainan Province. 2014;7(2):160-163. Available from: https://doi.org/10.1016/S1995-7645(14)60014-6. 